\title{
IDENTIFIKASI KARAKTERISTIK MORFOLOGI DAN HUBUNGAN KEKERABATAN SALAK PONDOH, SALAK MADU, SALAK GULA PASIR DI DESA SUMBER KECAMATAN WONOSALAM JOMBANG
}

\author{
Iska Zuliatin ${ }^{1}$, Mazidatul Faizah ${ }^{2}$ \\ ${ }^{1}$ Mahasiswa Fakultas Pertanian, Program Studi Agroekoteknologi, Universitas KH. A. \\ Wahab Hasbullah \\ ${ }^{2}$ Dosen Fakultas Pertanian, Program Studi Agroekoteknologi, Universitas KH. A. Wahab \\ Hasbullah \\ E-mail: mazidatul@unwaha.ac.id; iska.zuliatin@gmail.com
}

\begin{abstract}
ABSTRAK
Identifikasi Karakteristik Morfologi dan Hubungan Kekerabatan Salak Pondoh, Salak Madu, Salak Gula Pasir Di Desa Sumber Kecamatan Wonosalam.

Indonesia mempunyai jenis buah-buahan yang sangat banyak, salah satunya yaitu buah salak. Penelitian ini bertujuan untuk mengetahui ciri morfologi maupun kekerabatan antar tanaman salak pondoh, salak madu serta salak gula pasir di desa sumber kecamatan wonosalam kabupaten jombang. Penelitian dilaksanakan pada bulan februari-juni 2021 dengan memilih 5 sampel pada setiap jenis tanaman salak dengan parameter penelitian tinggi tanaman, panjang daun, panjang pelepah daun, kerapatan duri, tekstur duri, bentuk duri, warna permukaan atas daun dan warna permukaan bawah daun. Penelitian dilaksanakan secara langsung dan disusun menggunakan metode deskriptif dan dianalisis menggunakan analisis cluster berupa dendogram kemiripan. Berdasarkan pengamatan morfologi vegetatif ciri morfologi antara tiga jenis salak tersebut mempunyai beberapa ciri morfologi yang mirip, Diantara tiga jenis tanaman salak tersebut secara besar dikelompokkan mempunyai hubungan kekerabatan yang jauh dengan menunjukkan nilai kemiripan sebesar 54\%-74\%.
\end{abstract}

Kata Kunci : Hubungan Kekerabatan, Salak Madu, Salak Pondoh, Salak Gula Pasir

\begin{abstract}
Identification of Morphological Characteristics and Kinship of Pondoh Salak, Honey Salak, Sugar Salak in Sumber Village, Wonosalam District.

Indonesia has many types of fruits, one of which is salak. This study aims to determine the morphological characteristics and kinship between salak pondoh, salak honey and salak sugar in Sumber village, Wonosalam sub-district, Jombang district. The research was conducted in February-June 2021 by selecting 5 samples for each type of salak plant with the research parameters of plant height, leaf length, leaf midrib length, thorn density, thorn texture, thorn shape, color of the upper surface of the leaf and the color of the lower surface of the leaf. The research was conducted in a direct and compiled using descriptive method and analysis in the form of dendogram resemblance. Based on observations of vegetative morphology characteristics of morphology between the three types of salak has several similar morphological features, Among the three types of salak plants are large grouped have a distant kinship relationship by showing a similarity value of $54 \%-74 \%$.
\end{abstract}

Keywords : Kinship, Salak Honey, Salak Pondoh, Salak Sugar.

\section{PENDAHULUAN}

Desa mempunyai suatu karakter yang unik dan wilayah yang berbeda satu sama lain dalam hal masyarakat, ekonomi, budaya, dan lingkungan. Keunikan-keunikan desa tersebut dimungkinkan untuk dikembangkan sesuai dengan potensinya (Nur Qomariah et al., 2019).

Di Indonesia budidaya tanaman salak dikenal luas sejak jaman penjajahan Belanda. Tanaman salak mempunyai 
beberapa ragam, salah satunya mempunyai ciri khas yang menonjol pada rasa dan tampilan buahnya dan Selama ini terdapat banyak sentra produksi salak terkenal (Darmawati, 2019).

Menurut (Agung and Ningtias 2020) Ragam jenis tanaman salak diketahui sangat tinggi, Di Indonesia jawa memiliki banyak jenis salak seperti Pondoh, Ambarawa dan Swaru, Padang Sinempuan di Sumatera dan salak Bali. Sedangkan pada daerah wonosalam kabupaten jombang kebanyakan yang dibudidayakan adalah salak pondoh, karena Salak Pondoh memiliki nilai komersial dan ekonomi yang tinggi.

Salak adalah produk asli Indonesia yang dapat ditanam pada dataran rendah (Harahap et al., 2013) Salak yaitu salah satunya tanaman yang tergolong dalam familia Arecaceae, Karena Tanamanan salak adalah salah satu komoditas yang menarik untuk dikembangkan sebagai komoditas agar dapat memenuhi kebutuhan dalam negeri dan luar negeri atau biasa yang disebut dengan ekspor.

Salak (Salacca zalacca) (Gaertner) Voss adalah buah tropis yang salah satu ada di wilayah indonesia. Buah-buahan populer karena rasa yang manis dan renyah, serta bisa dimakan sebagai buah yang segar atau diolah sebagai manisan. Dibanding dengan jenis salak lainnya, salak bangkalan memiliki ciri khusus yang tersendiri yaitu memiliki kadar air yang lebih tinggi, sehingga akan terasa segar saat dimakan (Ariestin et al., 2015).

Pada tanaman salak memiliki daun majemuk dengan bentuk menyirip dan panjang kira-kira 3-7 m, tangkai daun pelepah serta anak daun berduri panjang, tipis dan banyak, duri tanaman salak berwarna kelabu sampai kehitaman. Anak daun bentuknya lanset dengan ujung meruncing berukuran sekitar $8 \times 85 \mathrm{~cm}$, sisi bawah keputihan oleh lapisan lilin (Christie and Lestari 2020). Sedangkan menurut penelitian (Fatimah 2013) Tanaman salak memiliki akar yang serabut dengan sistem perakaran dangkal sampai sedang, atau dengan kata lain bahwa penetrasi akar salak hanya mencapai kedalaman $10 \mathrm{~cm}$ hingga 50 $\mathrm{cm}$.

Berdasarkan adanya informasi dari petani mengenai salak di Desa Sumber Kecamatan Wonosalam diketahui bahwa ada 3 jenis salak yang ditemukan tersebut masih didasarkan pada ciri morfologi buah saja namun belum ada informasi mengenai ciri morfologi organ yang lain. diantara tiga jenis salak tersebut adalah salak pondoh, salak madu dan salak gula pasir. Akan tetapi jenis salak tersebut belum sepenuhnya dikenal masyarakat secara luas dan tidak ada penelitian sebelumnya mengenai tiga jenis ciri morfologi tanaman salak tersebut. Oleh sebab itu diperlukan penelitian mendasar mengenai identifikasi karakteristik morfologi dan hubungan kekerabatan salak pondoh, salak madu dan salak gula pasir di desa sumber kecamatan wonosalam.

\section{METODE PENELITIAN}

\subsection{Waktu dan Tempat}

Penelitian dilakukan di Desa Sumber Kecamatan Wonosalam kabupaten Jombang. Penelitian dimulai pada bulan Februari - Juni 2021.

\subsection{Bahan dan Alat}

Adapun alat yang akan digunakan dalam pengamatan morfologi adalah Penggaris, kamera, alat tulis, jangka sorong, ketas label dan cutter. Sedangkan bahan yang digunakan yaitu tiga jenis tanaman salak yaitu salak pondoh, salak madu dan salak gula pasir.

\subsection{Metode Penelitian}


Penelitian yang akan digunakan ini termasuk dalam penelitian deskriptif yang ditujukan untuk mendeskripsikan karakter morfologi salak dan menganalisis data dalam bentuk dendogram.

\subsection{Metode Penentuan Sampel}

Penelitian ini terdiri dari beberapa sampel yaitu Salak Pondoh (SP), Salak Madu (SM), dan salak Gula pasir (SGP). Penentuan sampel dipilih secara acak (Random) dengan memilih masing-masing 5 sampel tanaman setiap jenisnya jadi keseluruhan terdapat 15 sampel.

\subsection{Metode Pengumpulan Data}

Penelitian ini termasuk dalam Metode pengumpulan data dengan cara observasi atau pengumpulan data yang melalui pengamatan langsung secara cermat di lokasi penelitian serta wawancara kepada pemilik pekarangan tanaman salak. Dan memperhatikan studi literatur dan melampirkan dokumentasi

\subsection{Prosedur kerja}

Prosedur utama pada penelitian ini adalah Pengambilan Sampel pada setiap jenis tanaman salak diantaranya yaitu tanaman salak pondoh, salak madu dan salak gula pasir.secara porposif dari semua populasi salak di sentra budidaya Pengamatan dapat dilakukan dengan cara melihat perbedaan secara spesifik mengenai morfologi tanaman yang meliputi :

1) Batang tanaman : Dilihat mulai dari ciri-ciri maupun bentuk durinya

2) Daun : Dapat dilihat pada warna permukaan daun, susunan daun, jumlah anak daun, warna pelepah, panjang tangkai daun, panjang dan lebar anak daun, lebar dan panjang ujung daun, ujung daun, ibu tangkai daun.

3) Bunga : Dapat dilihat dari bentuk bunga jantan dan betina, susunan daun, warna benangsari, warna mahkota bunga

4) Buah: dapat dilihat dari bentuk sisik kulit, warna kulit, bentuk dan ujung buah, diameter buah, jumlah biji, warna biji, jumlah buah atau tandan, warna daging buah

5) Duri: Dapat dilihat dari bentuk besar kecilnya duri.

\subsection{Analisis Data}

Data kuantitatif dianalisis menggunakan metode UPGMA (Unweighted Pair-Group Method with Airthimetic Mean) dengan program NTSYS (Numerical Taxonomy and Multivariate System) versi 2.11 dengan analisis gerombol (Cluster) yang menghasilkan dendogram kemiripan untuk menilai kemiripan antar jenis salak di desa Sumber Kecamtan Wonosalam Kabupaten Jombang. Tahap dari pengelolahan data hasil penelitian dilakukan sebagai berikut :

a) Tahap awal analisis adalah melakukan edit terhadap data yang telah dikumpulkan yang bertujuan agar data yang akan dianalisis lebih akurat dan lengkap.

b) Setelah itu melakukan pengkodean terhadap tiap-tiap karakter dalam bentuk angka

c) Melakukan analisis cluster dengan metode UPGMA (Unweighted PairGroup Method with Airthimetic Mean)

d) Mengintrepertasikan cluster yang terbentuk dendogram

\section{HASIL DAN PEMBAHASAN}

\subsection{Hasil Pengamatan Morfologi}


Pada pengamatan morfologi vegetatif salak pondoh, salak madu, salak gula pasir di desa sumber kecamatan wonosalam kabupaten jombang baik berupa data kuantitatif maupun data kualitatif dengan meliputi ciri morfologi mulai dari tinggi tanaman, kerapatan duri, tekstur duri, bentuk duri, panjang pelepah daun, panjang daun, warna permukaan atas daun, warna permukaan bawah daun. Berikut adalah observasi dan pengamatan dilapang.

Tabel 1. Data Kuantitatif Morfologi Vegetatif Salak Di Desa Sumber Kecamatan Wonosalam Kabupaten Jombang.

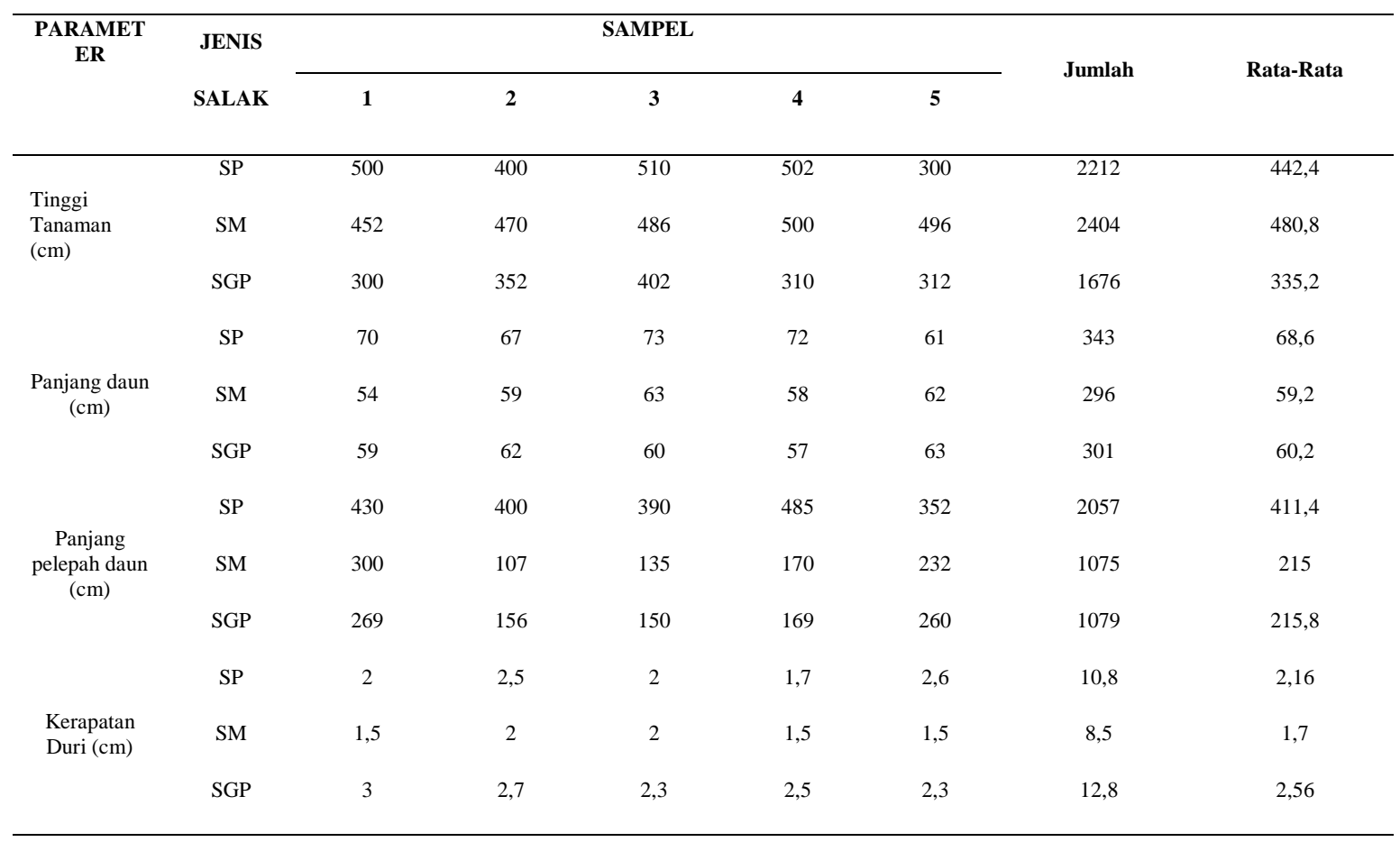

Tabel 2. Data Kualitaif Morfologi Vegetatif Salak di Desa Sumber Kecamatan Wonosalam Kabupaten Jombang.

\begin{tabular}{lccc}
\hline \multicolumn{1}{c}{ PARAMETER } & & JENIS SALAK & SGP \\
\cline { 2 - 4 } & SP & Agak Lunak & Kaku \\
\hline Tekstur Duri & Agak Lunak & Hijau Tua & Hijau Tua \\
$\begin{array}{l}\text { Warna Permukaan Atas } \\
\text { Daun }\end{array}$ & Hijau Tua & Hijau Keabuan & Hijau Keabuan \\
$\begin{array}{l}\text { Warna Permukaan } \\
\text { Bawah Daun }\end{array}$ & Runcing & Runcing & Runcing \\
Bentuk Ujung Daun & Tipis Lancip Kecil & Tipis Lancip Kecil & Tebal, lancip, kaku besar \\
Bentuk Duri & &
\end{tabular}


Berdasarkan tabel 1 dan Tabel 2 menunjukkan adanya perbedaan dan persamaan morfologi diantara ketiga jenis tanaman salak tersebut.

\subsection{Persamaan dan Perbedaan Morfologi Salak Di Desa Sumber}

Tanaman salak pondoh, salak madu, salak gula pasir mempunyai tinggi tanaman yang hampir sama yaitu berkisar dengan rata-rata $335,2-480,8 \mathrm{~cm}$ tergantung dari jenisnya. Hal ini sejalan dengan penelitian Harsoyo dalam (Harahap et al., 2013), Salak menyerupai pohon palem yang seolah-olah tidak berbatang, rendah dan tegak dengan tinggi tanaman salak antara 1,5-7 meter, tergantung dari jenisnya.

Di Desa Sumber Kecamatan Wonosalam salak pondoh mempunyai rasa yang manis, namun pada saat buah yang belum masak mempunyai rasa yang sepat. Tekstur dari daging buah salak pondoh yitu tidak berair dan mempunyai aroma yang sedang serta warna dari daging buah salak pondoh adalah putih susu hingga kuning krem, Salak pondoh juga mempunyai ketebalan daging buah 0,8-1,5 cm dengan jumlah pada tiap juring adalah 1-3. Hal ini sesuai dengan (Hidayati, 2013) menyatakan bahwa buah salak pondoh mempunyai sifat rasa manis (Tidak Sepat) mulai sejak buah masih muda dengan daging berwarna putih susu.

Menurut penelitian (Ristanti 2019) menyatakan bahwa tanaman salak madu tumbuh secara berumpun dan tinggi mencapai sekitar $7 \mathrm{~m}$, tetapi pertumbuhan rata-rata tidak melebihi $4,5 \mathrm{~m}$. Salak madu merupakan salah satu salak unggulan di Kabupaten Sleman dengan kualitas yang baik, daging buah yang tebal, tekstur yang lembut dan rasa manis yang khas seperti madu. Sedangkan di Desa Sumber Kecamatan Wonosalam salak madu memiliki ciri khas rasa yang manis dengan tekstur daging buah berair dan aroma daging buah yang lembut, namun pada saat buah belum masak memiliki rasa yang sepat. Salak madu memiliki tebal daging buah $0,1-1,0 \mathrm{~cm}$ dan mempunyai warna daging buah putih susu, putih kekuningan dengan tekstur yang elastis.

Menurut penelitian (Guntoro, 2004) dalam (Adijaya and Yasa 2014) menyatakan bahwa keunggulan dari salak gula pasir dapat dilihat dari segi kualitas maupun dari segi ekonomi, salak gula pasir memiliki daging buah yang rasanya jauh lebih manis dibanding dengan salak bali yang lainnya, karena rasa manis sudah dapat dirasakan sejak buah masih muda. Sedangkan di Desa Sumber Kecamatan Wonosalam salak gula pasir memiliki ciri khas rasa yang manis dengan tekstur daging buah berair dan aroma daging buah yang lembut, namun pada saat buah belum masak memiliki rasa yang sepat. Salak gula pasir memiliki tebal daging buah berkisar antara $0,1-1,0 \mathrm{~cm}$ dan mempunyai warna daging buah putih susu, putih kekuningan dengan tekstur yang elastis. Salak gula pasir mempunyai jumlah tandan pertangkai sekitar 1-4 dengan jumlah buah pertandan 18-36.

Jika dibandingkan dengan salak Sumatera Utara (Salacca sumatrana Becc) yang ada di daerah Kabupaten Tapanuli Selatan, tinggi dari ketiga salak yang ada di desa Sumber lebih pendek dari salak Sumatra Utara (Salacca sumatrana Becc) yang memiliki tinggi tanaman antara 6,8 m - 7,6 m (Ristanti, 2019). Hal ini diduga karena adanya perbedaan kesuburan tanah, cara budidaya, iklim atau sifat genetik.

Menurut salah satu petani ada suatu motivasi dalam pengembangan salak gula pasir karena dari secara ekonomis salak gula pasir memang memiliki harga yang jauh lebih tinggi dibandingkan dengan salak lain. Hal ini sesuai dengan 
pernyataan Sarmiati dkk. (2000) dalam (Adijaya and Yasa, 2015) yang menyatakan perbedaan kualitas (cita rasa) salak gula pasir berdampak terhadap nilai jualnya, dimana harga jual salak gula pasir jauh lebih tinggi dibandingkan dengan salak bali dengan perbandingan harga bisa mencapai 10:1.

Pada parameter panjang pelepah daunnya juga tidak terdapat adanya perbedaan, namun hanya saja panjang pelepah daun salak madu dan gula pasir sedikit lebih kecil dan agak lebih pendek dibandingkan dengan salak pondoh, begitupun dengan parameter panjang daun salak serta mempunyai karakteristik morfologi yang sama yaitu pada parameter warna permukaan atas daun yang berwarna hijau tuadan warna permukaan bagian bawah daunyang berwarna hijau keabuan serta memiliki ujung daun yang berbentuk meruncing.

Pada parameter kerapatan duri dari ketiga jenis salak mempunyai kerapatan yang berbeda-beda yang dimana salak pondoh mempunyai kerapatan duri sekitar 2,16 cm, salak madu $1,7 \mathrm{~cm}$, dan salak gula pasir $2,56 \mathrm{~cm}$. Namun dari ketiga jenis salak tersebut menunjukkan bahwa dari salak gula pasir memiliki tekstur duri yang keras, besar dan kaku dibandingkan dengan jenis salak pondoh dan madu.

\subsection{Hubungan Kekerabatan}

Berdasarkan dari sifat morfologi fegetatif dari ketiga jenis salak tersebut maka dapat diketahui hubungan kekerabatannya, agar dapat mengetahui hubungan kekerabatan maka dapat dianalisis dengan cara melihat hubungan kemiripan dari jenis salak tersebut dengan cara melihat hubungan kemiripan dari ketiga jenissalak tersebut menggunakan metode UPGMA (Unweighted Pair-Group Method with Airthimetic Mean) dengan program NTSYS (Numerical Taxonomy and Multivariate System) versi 2.11 dengan analisis gerombol (cluster) sehingga dapat menghasilkan dendogram kemiripan 15 sampel berdasarkan karakteristik morfologi yang terbentuk.

Menurut Cahyani (2004) dalam Trimanto (2010) indeks kemiripan dapat dikatakan jauh jika kurang dari 0,60. Pada indeks kemiripan yang mendekati angka 1 atau 1,00 maka dapat dikatakan mirip sepenuhnya, sedangkan jika jarak kemiringan itu mendekati angka 0 maka memiliki hubungan kekerabatan yang jauh. Berdasarkan angka biner (pengkodean) tersebut maka diperoleh hasil dendogram sebagai berikut :

a) Hubungan Kekerabatan Salak Pondoh dan Salak Madu

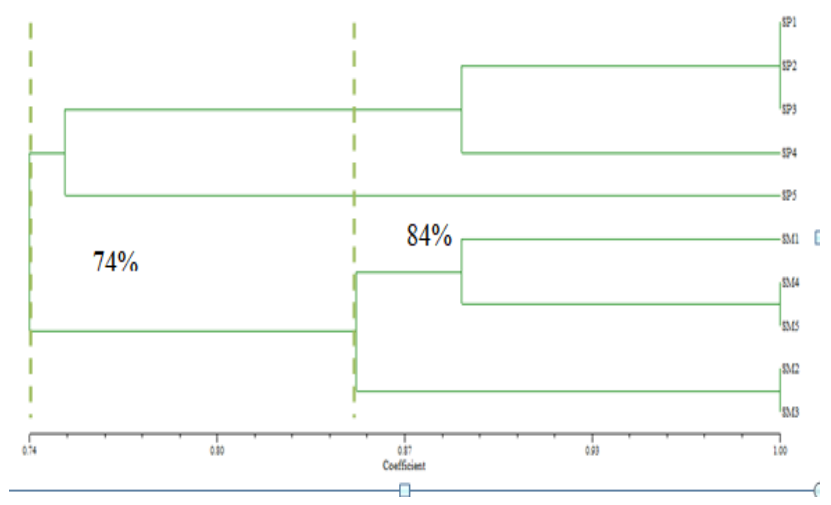

Gambar 1. Dendogram 10 pohon salak pondoh dan salak madu didesa sumber kecamatan wonosalam kabupaten Jombang 
Berdasarkan karakter morfologi vegetatif, salak pondoh dan salak madu di desa sumber kecamatan wonosalam memiliki kekerabatan dengan kemiripan sebesar $74 \%$ dengan nilai koefisien $74 \%$ $84 \%$. Hal ini menunjukkan bahwa hubungan kekerabatan antara salak pondoh dan salak madu hampir dekat. Pada hasil tersebut sesuai dengan pernyataan Cahyarini (2004) didalam (Faizah et al., 2020) bahwa indeks kemiripan dikatakan jauh jika kurang dari $0,60 \quad(60 \%)$ dan indeks kemiripan mendekati angka 1 atau 1,00 (100\%) merupakan hasil yang mirip sepenuhnya.

\section{b) Hubungan Kekerabatan Salak Pondoh dan Salak Gula Pasir}

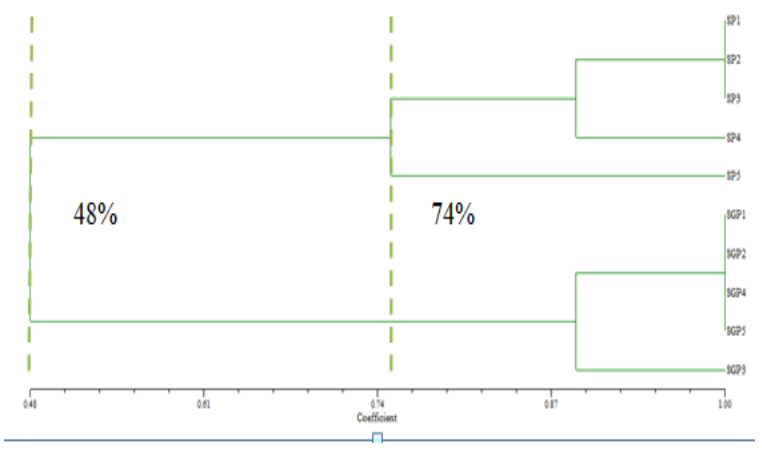

Gambar 2. Dendogram 10 pohon salak pondoh dan salak gula pasir di desa sumber kecamatan wonosalam kabupaten Jombang

Berdasarkan karakter morfologi vegetatif, salak pondoh dan salak gula pasir di desa sumber kecamatan wonosalam memiliki hubungan kekerabatan dengan kemiripan sebesar $48 \%$ dengan nilai koefisien 48\%-74\%. Hal ini menunjukkan bahwa hubungan kekerabatan antara salak pondoh dan salak gula pasir jauh. Pada hasil tersebut sesuai dengan pernyataan Cahyarini
(2004) didalam (Faizah et al., 2020) bahwa indeks kemiripan dikatakan jauh jika kurang dari 0,60 (60\%) dan indeks kemiripan mendekati angka 1 atau 1,00 $(100 \%)$ merupakan yang mirip sepenuhnya.

\section{c) Hubungan Kekerabatan Salak Madu dan Salak Gula Pasir}

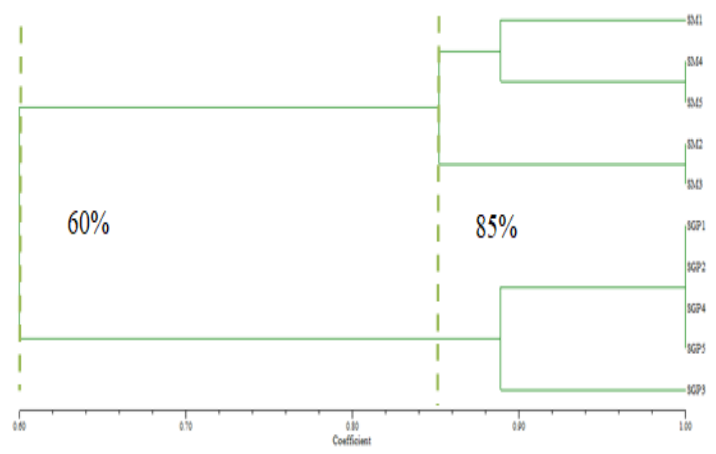

Gambar 3. Dendogram 10 pohon salak madu dan salak gula pasir di desa sumber kecamatan wonosalam kabupaten Jombang 
Berdasarkan karakter morfologi vegetatif, salak madu dan salak gula pasir di desa sumber kecamatan wonosalam memiliki hubungan kekerabatan dengan kemiripan sebesar $60 \%$ dengan nilai koefisien $60 \%-85 \%$. Hal ini menunjukkan bahwa salak madu dan salak gula pasir memiliki hubungan kekerabatan yang dekat. Pada hasil tersebut sesuai dengan pernyataan
Cahyarini (2004) didalam (Faizah et al., 2020) bahwa indeks kemiripan dikatakan jauh jika kurang dari 0,60 (60\%) dan indeks kemiripan mendekati angka 1 atau 1,00 (100\%) merupakan yang mirip sepenuhnya.

\section{d) Hubungan Kekerabatan Salak Pondoh, Salak Madu dan Salak Gula Pasir}

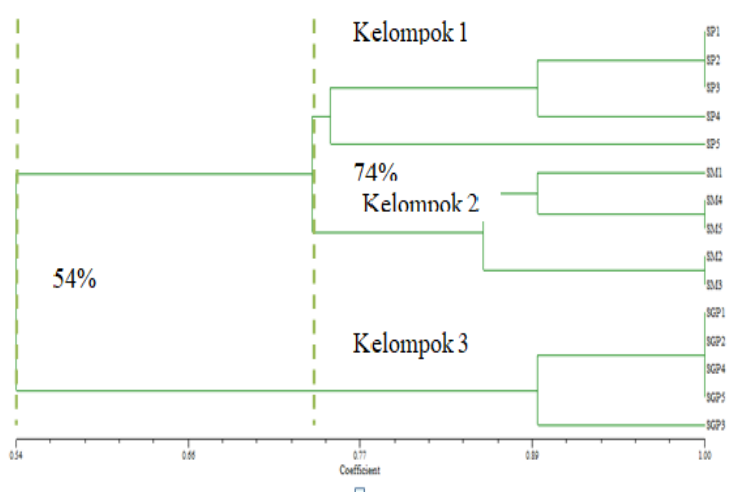

Gambar 4. Dendogram 15 pohon salak (Salacca zalacca) dari 3 jenis salak didesa sumber kecamatan wonosalam kabupaten Jombang.

Berdasarkan karakter morfologi vegetatif salak (Salacca zalacca) dari 3 jenis salak di desa sumber kecamatan wonosalam memiliki kekerabatan dengan kemiripan sebesar $54 \%$ dengan nilai koefisien $54 \%-74 \%$ yang dapat dikelompokkan kedalam 3 kelompok besar.

Secara umum hasil dendogram morfologis salak tidak mengelompokkan ke 15 sampel berdasarkan lokasi kebun tetapi berdasarkan persamaan karakter morfologisnya. pada kelompok 1 dan kelompok 2 menunjukkan hubungan kekerabatan yang hampir sama dengan nilai $74 \%$ pada nilai koefisien $74 \%-84 \%$ sehingga pada kelompok 1 serta kelompok 2 maka dapat dikatakan memiliki hubungan yang dekat. Sedangkan pada kelompok 1 dan kelompok 3 menunjukkan hubungan kekerabatan sama dengan nilai kemiripan sebesar $48 \%$ dengan nilai koefisien $48 \%$ $74 \%$ sehingga kelompok 1 dan kelompok 3 dapat dikatakan memiliki hubungan kekerabatan yang jauh, hal ini dikarenakan pada letakdan jarak pengambilansampel berjauhan dari sampel 1 ke sampel berikutnya namun dalam satu petak kebun yang sama sehingga kemungkinan dapat terjadi persilangansecara alami yang tanpa disilangkan oleh petani. pada kelompok 2 dan kelompok 3 menunjukkan angka kekerabatan dengan kemiripan sebesar $60 \%$ dengan nilai koefisien $60 \%-85 \%$ sehingga dapat dikatakan memiliki hubungan kekerabatan yang dekat.

Sedangkan pada kelompok 1, 2 dan 3 menunjukkan hubungan kekerabatan yang hampir sama dengan nilai kemiripan sebesar 54\% yang tidak berbeda jauh dengan kelompok 1 dan kelompok 3, hal ini dikarenakan memiliki hubungan 
kekerabatan yang jauh. Hal ini sesuai dengan penelitian menurut (Amzeri achmad et al., 2011) bahwa genotip yang berasal dari daerah yang sama tidak selalu berada dalam kelompok yang sama, semakin banyak persamaan karakter morfologi yang dimilki menunjukkan bahwa semakin dekat hubungan kekerabatan, sebaliknya semakin sedikit persamaan karakter yang dimiliki maka semakin jauh hubungan kekerabatannya.

\section{KESIMPULAN}

Salak Pondoh, Salak madu dan salak gula pasir mempunyai perbedaan morfologi yaitu kerapatan duri, rasa buah, bentuk buah, warna kulit buah, ukuran buah serta mempunyai hubungan kerabatan yang beda. Pada salak pondoh dan salak madu memiliki hubungan kekerabatan $74 \%$ dengan nilai koefisien 74\%-84\% bahwa kekerabatan antara salak pondoh dan salak madu hampir dekat. Sedangkan salak pondoh dan salak gula pasir memiliki hubungan kekerabatan dengan kemiripan $48 \%$ dengan nilai koefisien $48 \%-74 \%$ bahwa hubungan kekerabatannya adalah jauh. Pada salak madu dan salak gula pasir memiliki hubungan kekerabatan sebesar $60 \%$ dengan nilai koefisien $60 \%-85 \%$ sehingga menunjukkan hubungan kekerabatan yang dekat. pada kelompok 1, 2 dan 3 dalam 15 sampel menunjukkan hubungan kekerabatan yang hampir sama dengan nilai kemiripan sebesar 54\% yang tidak berbeda jauh dengan kelompok 1 dan kelompok 3, hal ini dikarenakan memiliki hubungan kekerabatan yang jauh.

\section{DAFTAR PUSTAKA}

Adijaya, I. Nyoman, and I. Made Rai Yasa. 2014. "Pengaruh Penjarangan Buah Terhadap Produktivitas Dan Kualitas Buah Salak Gula Pasir Pada Panen Raya." Inovasi Teknologi Pertanian
Spesifik Lokas (2004):445-51.

Adijaya, I. Nyoman, and I. Made Rai Yasa. 2015. "Pengaruh Pupuk Organik Dan Penjarangan Buah Terhadap Produktivitas Salak Gula Pasir." Jurnal Pengkajian Dan Pengembangan Teknologi Pertanian 18(2):195-206.

Agung, Nugroho Yuni, and Ningsih Elik Murni Ningtias. 2020. "Hubungan Morfologi Vegetatif Dan Generatif Salak Pondoh (Salacca Zalacca) Di Sentra Salak Pondoh Kabupaten Malang." Agrika: Jurnal Ilmu-Ilmu Pertanian 14(2):172-83

Amzeri achmad, Indradewa Didik, Daryono Budi Setiadi, \& Rachmawati Diah. (2011). Kekerabatan Jagung ( Zea mays L .) Lokal Madura Berdasarkan Karakter Morfologi dan Penanda RAPD Pendahuluan Metode Penelitian. 16(2), 227-235.

Ariestin, Y., Kuswanto, \& Ashari, S. (2015). Keragaman jenis salak Bangkalan \{Salacca zalacca (Gaertner) Voss \} menggunakan penanda morfologi dan analisis Isozim. J. Produksi Tanaman, 3(1), 35-42.

Christie, C. D. Y., and Nia A. L. (2020). "Identifikasi Morfologi Dan Kekerabatan Salak Di Jawa Timur." Fakultas Pertanian , Universitas Kahuripan Kediri Kediri, Indonesia 14:26-33.

Darmawati. (2019). Analisis Keragaman Salak (Salacca zalacca) Varietas Merah Berdasarkan Morfologi dan Anatomi di Kabupaten Enrekang.

Faizah, Mazidatul, Hari Prasetyono, and Mochamad Amaludin. 2020. "Kajian Morfologi Dan Hubungan Kekerabatan Salak Durian, Salak Nangka Dan Salak Apel Di Desa Kepuhdoko Kecamatan Tembelang Kabupaten Jombang." 3(1):147-53.

Fatimah, Siti. 2013. "Analisis Morfologi Dan 
Hubungan Kekerabatan Sebelas Jenis Tanaman Salak (Salacca Zalacca (Gertner) Voss Bangkalan." Agrovigor 6(1):1-15.

Harahap, H. M. Y., Bayu, E. S., \& Siiregar, L. A. . (2013). Identifikasi Karakter Morfologis Salak Sumatra Utara (Salacca sumatrana Becc.) Di Beberapa Daerah Kabupaten Tapanuli Selatan. Jurnal Online Agroekoteknologi, 1(3), 833-841.

Nur Qomariah, U. K., Darmawan, M. F., Shobirin, M. S., \& Ardiana, N. R. (2019). DEWASAREJO (Desa
Wisata Salak Jatirejo): Peningkatan Potensi Tanaman Salak Sebagai Peluang Usaha Baru di Jatirejo Diwek Jombang. Cendekia: Jurnal Pengabdian Masyarakat, 1(2), 93101.

https://doi.org/10.32503/cendekia.v1 i2.609

Ristanti, C. N. (2019). Analisis Ekonomi Dan Kelayakan Usahatani Salak Di Desa Rumah Lengko Kecamatan STM Hulu Kabupaten Deli Serdang. 